\section{Peripheral Neuropathy and Quality of Life of Adults Living with HIV/AIDS in Lubumbashi, Democratic Republic of Congo}

\section{Abstract}

Introduction: People living with HIV (PLHIV) have a higher life expectancy and therefore brings considerable health problems that concerns not only therapy but also the quality of life. The aim of this study is to determine the quality of life of patients infected with HIV presenting peripheral neuropathy (PN).

Methodology: A cross sectional descriptive research design was used. A time constrained method was used to sample 76 adults living with HIV/AIDS, presenting peripheral neuropathy at the center of excellence HIV/UNILU of Lubumbashi University in Lubumbashi city, DR Congo. The world Health organization quality of life scale brief versions were used to collect the data.

Results: The data of physical health and the environment present during this study high scores, essentially 23.76 and 23.48; the reasons used are the correct level of study, good care and economic recovery in our country. Psychological domain has a score of 17.10; the reasons used are the contribution of psychologists and support groups as well as community nurses who assist PLHIV. The social domain presents a low score, 7.5 because of the stigma and discrimination very thorough in our country.

Conclusion: The effectiveness of care is judged by its impact on the quality of life of patients; nowadays the therapy must satisfy the doctors and the patients.

Keywords: HIV; Quality of life; Domain score; Chronic painful symptoms

Katabwa Kabongo Joe ${ }^{1}$, Tshibangu Manyonga $\mathrm{E}^{2}$, Ntambwe Mwembo $A^{3}$ Wembonyama Stani ${ }^{4}$, Mukendi Kavulu $\mathrm{R}^{5}$ and Mutombo Lukusa $\mathbf{V}^{6}$

1 Department of Internal Medicine, University of Lubumbashi, DR Congo

2 Department of Psychology, Centre Excellence UNILU, University of Luumbashi, DR Congo

3 Department of Pediatrics, University of Lubumbashi, DR Congo

4 Department of Public Health, University of Lubumbashi, DR Congo

5 Neurologist, Complex Hospital Regional of Mons, St. Joseph, Catholic University of Leuven, Belgium

6 Department of Neurology, University of Mbuji Mayi, DR Congo

Corresponding author:

Katabwa Kabongo Joe

\title{
$\equiv$ Joekabongo2004@gmail.com
}

Department of Internal Medicine, University of Lubumbashi, DR Congo.

Tel: +243997017104

Received: July 13, 2016; Accepted: November 22, 2016; Published: November 25, 2016

\begin{abstract}
Abbreviations: HRQOL: Health-Related Quality of Life; PLHIV: People Living with HIV/AIDS; NP: Peripheral Neuropathy; QOL: Quality of Life; ARV: Antiretroviral; DN4: Scale of Pain of Neuropathy; EVA: Visual Analogy Scale; IO: Opportunistic Infections
\end{abstract}

\section{Introduction}

People living with HIV/AIDS (PLWHA) have a hope of life higher than before. So, they have chronic health problems and are not only concerned about the capacity of treatment to prolong life, but also the quality of life [1]. Peripheral neuropathy (NP) is a condition associated with functional limitations that can affect the quality of life of patients. Chronic painful symptoms experienced during poly peripheral neuropathies can have a considerable impact on the life of an individual and may be associated with anxiety, depression and loss of mobility and independence.

Studies on HIV and the quality of life showed that, compared to patients with other chronic diseases, patients with symptoms of HIV have marked their Health-Related Quality of Life (HRQOL) as poor, while patients with asymptomatic HIV scored better [2].

The concept of quality of life of the patient is indicative of a profound change in the way to practice medicine, what formerly 
based solely on clinical signs observed by caregivers, yields little by little the place to a nearest medicine patients and their therapeutic wishes. Indeed, the quality of life more refers to a sense of well-being to an absence of organic disease or simple state of health. "I attach more prizes to the quality of my life the number of days she could count ": this quote attributed to Socrates illustrates perfectly the concept of quality of life [3].

Who cited by Rosser RM, Kind P. defines the quality of life as "the perception that an individual's place in the existence, in the context of the culture and system of value in which he lives, in relation to its objectives, expectations, standards and concerns." The questionnaire HRQOL, from who, aims to achieve this measure [4].

Measurement of the quality of life is based generally on the measurement of four to six dimensions including physical state (autonomy, physical abilities), somatic sensations (pain), psychological state (anxiety, emotional) and social relations [5].

The objective of our study is to determine the quality of life (QOL) of HIV-infected patients with peripheral neuropathy.

\section{Materials and Methods}

Our study is cross, carried out in the Centre of Excellence HIV/ AIDS at the University of Lubumbashi on 76 patients with Peripheral Neuropathy (NP). All are on ARVS since at least 6 months membership and compliant to treatment. Patients with NP have been selected at the heart of our previous study of the NP [6]. The clinical peripheral neuropathy diagnosis using a thorough neurological exam looking for superficial and deep sensitivity disorders, the tendon reflexes and strength of the affected members, the pain as it was assessed using 2 scales: Scale visual analog (EVA) to evaluate the intensity and screening of neuropathic pain (DN4) scale for diagnostic orientation.

\section{Study environment}

The Centre of Excellence was born on December 22, 2006. It operates at the hospital reference provincial Jason Sendwe in Lubumbashi R. D. Congo. So far we have 4379 patient's enrolled $36.51 \%$ male and $63.48 \%$ female for adults and $21.94 \%$ of children.

The center of excellence enjoys a direct support of the Government and other international partners. It has its different department's management data and amenities, Opportunistic Infections (OI), psychological follow-up monitoring and disclosure of HIV status of children. Accessibility to our services is good and geographically and financially because all care is free.

For the collection of data, the valid questionnaire Brief HRQOL, served us as an information gathering tool, it was administered by us even to each patient.

The HRQOL consists of 26 articles; each element uses a five-point Likert type scale. In addition, demographic and medical data are obtained from specific questions added to the instruments, and from records.

These items will be distributed in four areas. The four domains of quality of life are:
- Physical health and the level of independence (7 points);

- $\quad$ Psychological well-being (8 points);

- Social relations (3 items);

- $\quad$ Environment (8 points).

There are also two elements which will be considered separately: one that will query on the overall perception of the individual's quality of life and the other on the overall perception of the individual's health. Each element uses a five-point Likert type scale. Most scores will be resized in a positive sense where higher scores indicate the quality of life more high [6]. Participants were asked about their experience in the above areas in the two weeks preceding the collection of the data.

Analysis and treatment of the data were made using SPSS 11.0 software and Epi Info version 3.5.1 and Excel 2010. Descriptive statistics was expressed in average. The parametric tests (mean and standard deviation) were used. A value $p \leq 0.05$ or less is considered significant. Comparisons between data were made by test student's $\mathrm{t}$ and Chi-square test. The anonymity and confidentiality of the data collected as a result of clinical and complementary examinations were observed.

\section{Results and Discussion}

Our study looked at 76 respondents whose age ranged from 24 to 65 years; the average age of the participants is 39 years old. Sex male female ratio is $1.2 ; 50 \%$ of our respondents were married; $51.32 \%$ have a level of higher or University study, the most common is the common Kampemba $34.21 \%$.

There's no difference between the domains of quality of life and marital status. In the field of social relations, it was however noted a statistically significant difference $\left(p^{1 / 4} 0.030\right)$ for subjects who have been married compared to widowers. Comparisons of average quality of life scores showed significant differences between physical health $(p=0.000)$, psychological $(p=0.000)$, relations social (0.033) and the environment (0.040) and compared to the level of education, lower scores were observed in patients not enrolled in school compared to those with a primary, secondary and tertiary education (Table 1).

The variable time since diagnosis of HIV indicated that subjects who knew their HIV status 2 to 4 years ago received average scores higher in the field of social relationships over those who come to know their status since less than 2 years. Independent sample t-test was conducted to determine whether significant differences exist between the domains of quality of life (physical, psychological, social and environmental) of participants and individuals without symptoms of the NP. The quality of life among participants with the NP presents significantly lower scores in the physical domain $(p=0.013)$ and psychological $(p=0.020)$.

For our study the average score of the physical realm is 23.76 , the psychological domain gives us an average of 17.10, the social field has an average of 7.5 while the average of the field of the environment is 23.48. The illustrations in this table show the average score for each indicator. It should be noted that the age between 41-50 age group has the lowest score in the area of 
physical health while the respondents higher age at age 60 have a score high in the psychological and environmental fields (Table 2).

Our study focused on 76 patients with average age of 39 years, all followed by the Centre of excellence for Peripheral Neuropathy (NP), the clinical diagnosis was made after an examination of thorough neurological and pain assessment is done with scales DN4 and EVA, the study of Juvenal et al. at Hospital of Rulindo in Rwanda which focused on 185 patients gave a meanage of 38.7 years, the diagnosis was also clinical [7], in North of the India study an average of 32.4 years found [8].

\section{Physical health}

It reveals the impact of the disease on daily physical activity of patients, the disease, the lack of will and initiative, as well as the

Table 1 Characteristics demography que $(n=76)$.

\begin{tabular}{|c|c|c|c|}
\hline Age & & Frequency & Pierce \\
\hline & $<30$ & 24 & 31.58 \\
\hline & $31-40$ & 23 & 30.26 \\
\hline & $41-50$ & 12 & 15.79 \\
\hline & $51-60$ & 12 & 15.79 \\
\hline & $>60$ & 5 & 6.58 \\
\hline \multicolumn{4}{|l|}{ Sex } \\
\hline & Female & 35 & 46.05 \\
\hline & Male & 41 & 53.95 \\
\hline \multicolumn{4}{|l|}{ Marital status } \\
\hline & Marie (e) & 38 & 50.00 \\
\hline & Widowed & 5 & 6.58 \\
\hline & Divorce (e) & 2 & 2.63 \\
\hline & Single & 31 & 40.79 \\
\hline & Cohabiting & 0 & 0.00 \\
\hline \multicolumn{4}{|l|}{ Education } \\
\hline & Primary & 0 & 0.00 \\
\hline & Secondary & 37 & 48.68 \\
\hline & Higher or Univ & 39 & 51.32 \\
\hline \multicolumn{4}{|l|}{ Occupation } \\
\hline & Agriculture & 5 & 6.58 \\
\hline & $\begin{array}{l}\text { Private } \\
\text { company }\end{array}$ & 12 & 15.79 \\
\hline & $\begin{array}{c}\text { Public } \\
\text { enterprise }\end{array}$ & 5 & 6.58 \\
\hline & Student & 11 & 14.47 \\
\hline & $\begin{array}{c}\text { Public } \\
\text { function }\end{array}$ & 8 & 10.53 \\
\hline & Housewife & 3 & 3.95 \\
\hline & $\begin{array}{l}\text { Liberal } \\
\text { profession }\end{array}$ & 23 & 30.26 \\
\hline & Sale & 9 & 11.84 \\
\hline \multicolumn{4}{|l|}{ Provenance } \\
\hline & Annex & 8 & 10.53 \\
\hline & Kamalondo & 6 & 7.89 \\
\hline & Kampemba & 26 & 34.21 \\
\hline & Katuba & 12 & 15.79 \\
\hline & Kenya & 7 & 9.21 \\
\hline & Lubumbashi & 14 & 18.42 \\
\hline & Ruashi & 3 & 3.95 \\
\hline
\end{tabular}

Table 2 Relationship of average school scores $(n=76)$.

\begin{tabular}{|c|c|c|c|c|c|}
\hline \multirow[t]{6}{*}{ Age } & & $\begin{array}{l}\text { Health } \\
\text { physics }\end{array}$ & $\begin{array}{c}\text { Health } \\
\text { psychological }\end{array}$ & $\begin{array}{c}\text { Social } \\
\text { relationship }\end{array}$ & Environment \\
\hline & $\leq 30$ & 23.73 & 16.91 & 7.41 & 23.17 \\
\hline & $31-40$ & 25.05 & 17.84 & 7.94 & 24.95 \\
\hline & $41-50$ & 20.83 & 15.75 & 7.83 & 22.25 \\
\hline & $51-60$ & 25.83 & 17.50 & 7.00 & 24.33 \\
\hline & $>60$ & 23.60 & 18.40 & 7.00 & 25.00 \\
\hline \multicolumn{6}{|l|}{ Sex } \\
\hline & Female & 24.11 & 17.00 & 7.28 & 23.57 \\
\hline & Male & 23.46 & 17.19 & 7.78 & 23.41 \\
\hline \multicolumn{6}{|c|}{ Marital status } \\
\hline & Marie (e) & 23.44 & 16,81 & 7.68 & 23,23 \\
\hline & Widowed & 23.60 & 18.40 & 7.00 & 24.80 \\
\hline & Divorce (e) & 23.50 & 16.50 & 7.00 & 24.50 \\
\hline & Single & 24.19 & 17.29 & 7.51 & 23.51 \\
\hline & Cohabiting & 0.00 & 0.00 & 0.00 & 0.00 \\
\hline \multicolumn{6}{|c|}{ Education } \\
\hline & Primary & 0.00 & 0.00 & 0.00 & 0.00 \\
\hline & Secondary & 24.13 & 16.97 & 7.29 & 23.40 \\
\hline & $\begin{array}{l}\text { Higher or } \\
\text { Univ }\end{array}$ & 23.41 & 17.23 & 7.79 & 23.56 \\
\hline \multicolumn{6}{|c|}{ Occupation } \\
\hline & Agriculture & 25.60 & 18.00 & 9.60 & 22.40 \\
\hline & $\begin{array}{l}\text { Private } \\
\text { company }\end{array}$ & 23.66 & 16.08 & 7.50 & 22.25 \\
\hline & $\begin{array}{l}\text { Public } \\
\text { enterprise }\end{array}$ & 23.06 & 16.80 & 7.40 & 24.00 \\
\hline & Student & 21,72 & 17.18 & 7.72 & 23.45 \\
\hline & $\begin{array}{c}\text { Public } \\
\text { function }\end{array}$ & 24.12 & 17.00 & 8.37 & 24.50 \\
\hline & Housewife & 26.60 & 18.00 & 7.00 & 24.33 \\
\hline & $\begin{array}{l}\text { Liberal } \\
\text { profession }\end{array}$ & 23.96 & 17.00 & 7.00 & 23.82 \\
\hline & Sale & 23.66 & 18.11 & 7.20 & 23.44 \\
\hline \multicolumn{6}{|c|}{ Provenance } \\
\hline & Annex & 22.86 & 17.00 & $7.62 \mathrm{~mm}$ & 23.13 \\
\hline & Kamalondo & 24,33 & 19.50 & 8.30 & 24.16 \\
\hline & Kampemba & 23.92 & 15.96 & 8.03 & 22.50 \\
\hline & Katuba & 23.17 & 17,17 & 7.17 & 23.66 \\
\hline & Kenya & 23.86 & 17.57 & 7.00 & 23.86 \\
\hline & Lubumbashi & 24.35 & 17.78 & 7.00 & 24.64 \\
\hline & Ruashi & 23.00 & 18.00 & 7.00 & 24.66 \\
\hline
\end{tabular}

${ }^{*} \mathrm{p}=0.05$

ability to work. Our score average is 23.76 ; the good score posted by our patients is first linked to clinical stability that characterizes $75 \%$ of patients in our cohort, the centre of excellence has developed in its midst of Opportunistic Infections (IO) support capabilities these past two years that allowed to collect satisfactory clinical results. Increasingly in the national protocol, common usage and availability of antidepressants so slightly relieves pain of patients, thereby improving the physical capabilities.

Our cohort is increasingly made up of younger subjects, $76 \%$ have intermediate younger than 50 years with a higher level of study 
of $51 \%$; While in the Rwandan study present a score of 12.72 and a low level of study, it criminalizes the geographical location and socio-economic region in which the study was conducted [7]. A study showed a correlation between a low score and the low level of study of patients, North of the India found a score of $17.7 \%$ with $33 \%$ of participants with a level of academic study [8].

\section{Psychological field}

This area addresses much more self-esteem which in case is initiated by the stigma and discrimination of which the most part of our patients are victim. The psychological field reveals a score of 17.10 on average which is high for the simple and good reason than psychological support is actually integrated with the centre of excellence at the University of Lubumbashi. Patients have a psychological follow-up voiced support at home by support structures composed primarily by psychologists clinical and school as well as PLHIV commutes nurses, this begins with the disclosure in adolescents and continues into adulthood. Juvenal et al. years their study reinforces our results with a score between 15 and 20, through support groups and psycho-social support enjoyed by Rwandan patients. Uwimana and Struthers in their study, show that PLHIV are in need of psychological support therefore for them to accept their State [9]. For Murphy et al. when a person accepts are State, her HIV status, she takes control of his life, of his destiny and presented a good esteem self [10]. Wig et al. in their study reveal a correlation between the high study level and a good score in the psychological field which strengthens our results, because more than half of our patients have a level of academic study [8].

\section{Social domain}

The social field is relative to the interactions with the environment, the quality of relationship with others, as well as sexual activity. The average of our study is low in the range of 7.5; This is explained by the fact that the quality of inter individual relations is bad, entourage and others maintain the discrimination and stigma despite a sense of self, our patients are unable to free themselves from the negative image that others have of them, we register very little wedding to birth in our PLHIV, denial of sex is very thorough. The study of Juvenal et al. who report an average intermediate 13.39; here are incriminated the attitude of the community towards PLWHA and a stigma that has remained important in the entourage of the patient [7], Hader in his study mentions a very low score in women and $[10,11]$ men, in our study, the difference is not significant [10]. Hader et al. in their study explain a lower score in women because discrimination based on sex and secondly to the fact that the woman tends to sacrifice his life to the dependent on others. The level of study does not affect the social sphere in our study [10-12], Wig et al. support it also in his study [8].

\section{Environmental field}

It is access mainly on financial resources, lab our, accessibility to health care, security, freedom, the opportunity to participate in income-generating activities. The average of score is high either 23.48; the revival of the economy in our country confers some financial to Congolese security, PLHIV are also concerned, access to care is totally free to the Centre of Excellence that enjoys sustained attention and benevolent local government, PLWHA are also direct microcredit support. The study of Juvenal et al. reported an average intermediate 12.57 , due to the geographic situation which is predominantly rural with a quite difficult accessibility, of the overall financial situation of the province and even the lack of family to PLHA financial support, study was conducted in rural unlike ours which was conducted in the city. Uwimana and Struthers also in his study reported that the financial contribution is the real problem of PLHIV in Rwanda [9]. For Wig et al. the family constitutes the main financial support of patients in the North of India [8].

\section{Limitation of the study}

Our sample is very limited, represents less than $5 \%$ of our total cohort, peripheral neuropathy diagnosis is essentially clinical, with an assessment of pain by two standard scale (DN4, EVA).

The assessment of the quality of life in patients without peripheral neuropathy, our cohort is underway we cannot extend these results to all of our patients; the results will be compared after.

\section{Conclusion}

Our quality of life study looked at 76 persons all included in the programme of care HIV Center of Excellence at the University of Lubumbashi. PLWHA are tracked for peripheral neuropathy 2 years and members are compliant to treatment. The average score of the physical realm is high either 23.76 or the reasons advanced in our midst are the high study level and good support in General. The score of the psychological domain is good 17.10 and reasons, good psychological counseling by psychologists help through support groups and a follow-up at home by the community nurses. Social reports a score with a low average of 7.5; the bad interaction, the poor understanding of disease through the entourage and this despite a good esteem that presents PLHIV.

The environmental area has a good score with the average of 23.48; we found a satisfactory financial situation in general in our milieu, a free access to care with all the services offered by the centre of excellence, which itself enjoys considerable support from the local government. To judge the effectiveness of a treatment, by its ability to preserve or improve the lives of patients, that is its impact on the quality of life of patients, remains an ambitious exercise and difficult. Our study is certainly limited by its low sample, its means essentially diagnostic clinical, nevertheless we wanted to show the health professional that nowadays the therapy must meet and the doctor and the patient.

\section{What is known about?}

- The peripheral neuropathy is associated with functional limitations and thus affects the quality of life of patients.

- Chronic pain has a considerable impact in patients and is even associated with anxiety, depression and loss of mobility of the independence.

- Patients living with HIV with opportunistic infections have their Health Related Quality of Lif (HRQOL) very poor. 


\section{What is our contribution?}

- The impact of the disease on daily physical activity in our patients is low, due to the fact that $75 \%$ of patients have clinical stability.

- The psychological field that addresses self-esteem has also our patients a score high; 17.10 ; because a good psychological support coupled with home visits.

- The quality of relations with others, as well as sexual activity in our patients are bad because despite a good feel, our patients are unable to free themselves from the negative image made in the entourage of them. 


\section{References}

1 Castiel D (2004) The economic calculation in health methods and critical analysis. Rennes NPHS, USA.

2 WHO (1995) WHOQOL-100: THE 100 Questions with Response Scales. Division of mental health, World Health Organization, Geneva, Switzerland.

3 Bergner M (1989) Quality of Life, health status and clinical research. Medical Care 27: 148-156.

4 Rosser RM, Kind PA (1978) scale of assessments of states of illness, there is a social consensus? Inter J Epidemiol 7: 347-358.

5 Bucquet D, Condon S, Ritchie K (1990) The French version of the Nottingham Health Profile. A comparison of item weights with those of the source version. Soc Sci Med 30: 829-835.

6 Joe KK (2015) Peripheral neuropathies associated with HIV/AIDS. A clinical study in patients infected with HIV AIDS cases HIV Excellence Centre/University of Lubumbashi the pan. Afr Med J pp: 12-17.
7 Juvenal B, Anthea R (2012) Peripheral neuropathy and quality of life of adults living with HIV/AIDS in the Rulindo district of Rwanda, SAHARA- J. Journal of Social Aspects of HIV/AIDS 9: 88-94.

8 Wig N, Lekshmi R, Pal H, Ahuja V, Mittal CH, et al. (2006) The impact of HIV/AIDS on quality of life: a cross sectional study in North India. Indian J Med Sci 60: 1-11.

9 Uwimana J, Struthers P (2007) Met and unmet palliative care needs for people living with HIV/AIDS in Rwanda. Journal of Social Aspects of HIV/AIDS 4: 575-585.

10 Hader S, Smith D, Moore J, Holmberg S (2001) HIV infection in women in the United States: status at the millennium. J Am Medl Assoc 285: 1186-1192.

11 Stewart A, Ware JZ, Well-Bein G (1999) Measuring Functioning. The Medical Outcome Survey Approach. Duke University Press, USA.

12 Dos Santos ECM, Junior IF, Lopes F (2007) Quality of life of people living with HIV/AIDS in Sao Paulo, Brazil. Rev Saude Publica 41: 64-71. 